Erratum

\title{
Erratum: Borrego-Sánchez, A., et al. Molecular Modeling of Adsorption of 5-Aminosalicylic Acid in the Halloysite Nanotube. Minerals 2018, 8, 61
}

\section{Minerals Editorial Office}

MDPI AG, St. Alban-Anlage 66, 4052 Basel, Switzerland

We would like to change the first one of authors' affiliations of paper [1] from:

Andalusian Institute of Earth Sciences, University of Granada, Av. de las Palmeras 4, 18100 Granada, Spain to the correct version, as follows:

Andalusian Institute of Earth Sciences, CSIC-University of Granada, Av. de las Palmeras 4, 18100 Granada, Spain We apologize for any inconvenience brought to the readers.

\section{Reference}

1. Borrego-Sánchez, A.; Awad, M.E.; Sainz-Díaz, C.I. Molecular Modeling of Adsorption of 5-Aminosalicylic Acid in the Halloysite Nanotube. Minerals 2018, 8, 61. [CrossRef]

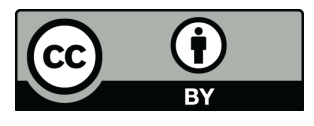

(C) 2018 by the author. Licensee MDPI, Basel, Switzerland. This article is an open access article distributed under the terms and conditions of the Creative Commons Attribution (CC BY) license (http://creativecommons.org/licenses/by/4.0/). 